\title{
High Performance and a Very Small Footprint
}

\author{
A new generation of manually loaded compact cleaning machines is \\ designed for improved performance and highly cost-effective operation.
}

\begin{abstract}
fter redesigning its fast autoAmated cleaning machine (Multiclean-FX), Höckh has now turned its attention to its range of manually loaded compact cleaning systems. According to the manufacturer, the third generation of Lean Concept systems (LC-III) is more powerful and easier to maintain while retaining the same compact dimensions as its predecessors. The model that is only $1250 \mathrm{~mm}$ wide and 1900 $\mathrm{mm}$ deep is particularly practical, because it can be positioned with its back against a wall.
\end{abstract}

Up to six batches per hour The new range of compact machines is used with standard baskets which are $530 \times 320 \times 200$ $\mathrm{mm}$ in size and, depending on the complexity of the cleaning programme, can process up to six batches per hour. With two cleaning circuits, ultrasound and three-stage fine filters, it is perfectly equipped for small and mediumsized businesses which require high-

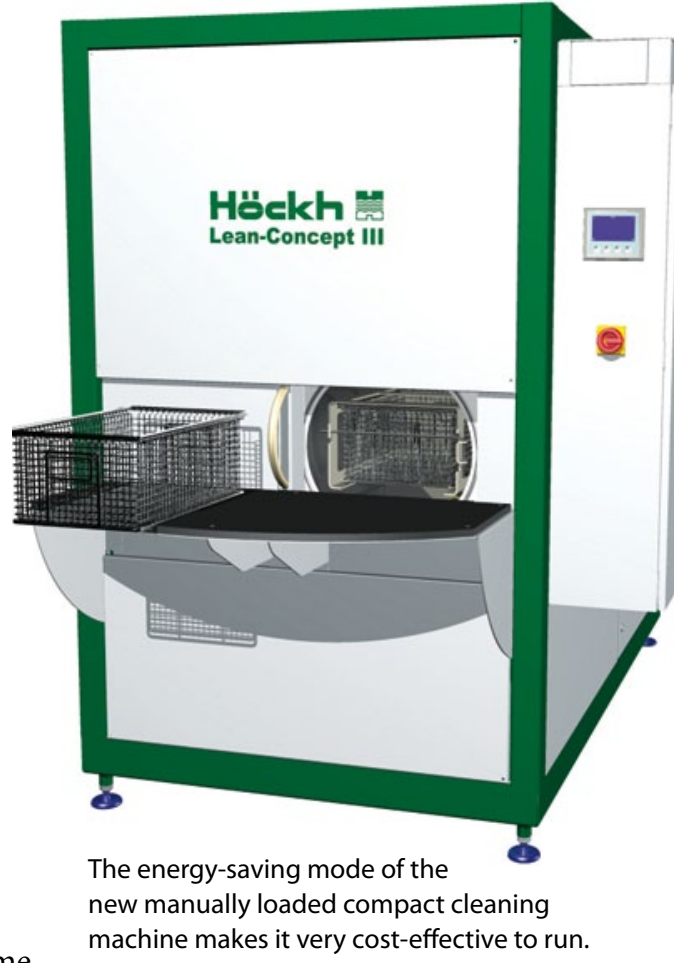

quality cleaning processes. This includes, in particular, companies that produce turned or pressed parts and manufacturers of medical devices.
Energy-saving function reduces electricity consumption

The entire cleaning process takes place in a full vacuum. This ensures that it operates safely with all common solvents (hydrocarbons, modified alcohol or perchloroethylene). The standard distillation unit, which has a heat recovery system, and the residual distillation unit, which automatically removes any oil, significantly reduce the amount of maintenance needed and ensure that the solvent baths last for several years.

A particularly useful feature for small-scale users is the extended energy-saving function, which reduces electricity consumption in stand-by mode to an absolute minimum and allows for highly cost-effective part-time operation. I

\section{For more information, please contact:}

Höckh Metall-Reinigungsanlagen GmbH, Markus Mitschele,

Neuenbürg, Germany, Tel. +497082 410931 10,

www.hoeckh.com, info@hoeckh.com

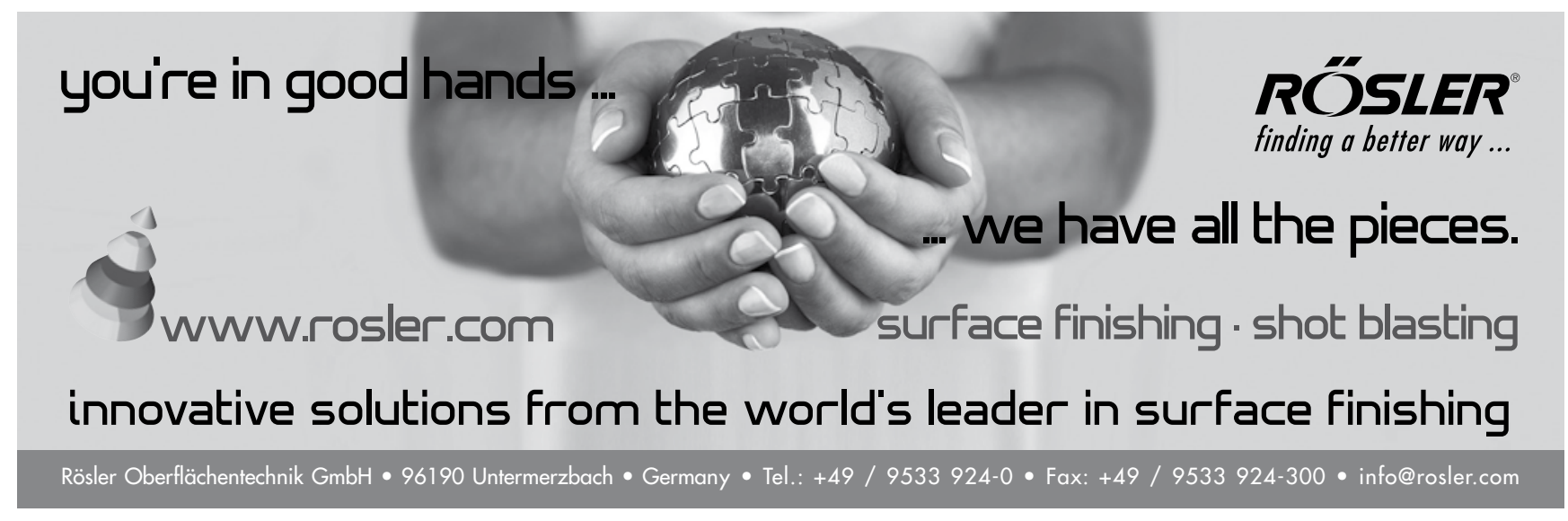

